\title{
A pedagogia de Maria Montessori para a educação na infância
}

\author{
The pedagogy of Maria Montessori for education in children
}

La pedagogía de María Montessori para la educación en la niñez

\begin{abstract}
Jaqueline Delgado Paschoal - Universidade Estadual de Londrina | Departamento de Educação | Londrina | PR | Brasil. E-mail: jaquelinedelgado@uol.com.br
\end{abstract}

Maria Cristina Gomes Machado - Universidade Estadual de Maringá | Departamento de Fundamentos da Educação | Maringá | PR | Brasil. E-mail: mcgmachado@uem.br

Resumo: Maria Montessori reconheceu a infância como um período fértil no qual as potencialidades se desenvolvem rapidamente, e ressaltou a livre expressão e um ambiente adequado e motivador como fatores fundamentais para despertar a inteligência das crianças, de modo a prepará-las para a vida adulta. Ao considerar que a criança é um pequeno explorador do mundo ao seu redor, defendeu a liberdade de ação nessa interação, para a qual propôs a educação dos sentidos como elemento importante no trabalho do professor. O tripé atividade-individualidade-liberdade formava a base de seu trabalho e os estímulos externos eram considerados como determinantes para o desenvolvimento infantil. O propósito desse estudo de caráter bibliográfico é apresentar a concepção de Montessori sobre a infância e o trabalho pedagógico com crianças em espaços coletivos. O intuito é contribuir para a formação continuada de professores da infância no sentido de destacar a atualidade da proposta montessoriana no contexto escolar.

Palavras-chave: Educação. Montessori. Criança.

Abstract: Maria Montessori recognized childhood as a fertile time in which the potentialities develop rapidly, and emphasized free expression and a suitable and motivating environment as fundamental factors to awaken children's intelligence in order to prepare them for adulthood. Considering that the child is a small explorer of the world around him, he defended freedom of action in this interaction, for which he proposed the education of the senses as an important element in the work of the teacher. The tripod activity-individuality-freedom formed the basis of his work and external stimuli were considered as determinants for child development. The purpose of this bibliographic study is to present the Montessori conception about childhood and the pedagogical work with children in collective spaces. The intention is to contribute to the continuing education of teachers of childhood in order to highlight the relevance of the Montessor proposal in the school context.

Keywords: Education. Montessori. Child.

Resumen: María Montessori reconoció la niñez como un período fértil en el cual las potencialidades se desarrollan rápidamente, y resaltó la libre expresión y un ambiente adecuado y motivador como factores fundamentales para despertar la inteligencia de los niños, de modo a prepararlos para la vida adulta. Al considerar que el niño es un pequeño explorador del mundo a su alrededor, defendió la libertad de acción en esa interacción, para la cual propuso la educación de los sentidos como elemento importante en el trabajo del maestro. El trípode actividad-individualidadlibertad formaba la base de su trabajo y los estímulos externos eran considerados como determinantes para el desarrollo infantil. El propósito de este estudio de carácter bibliográfico es presentar la concepción de Montessori sobre la niñez y el trabajo pedagógico con niños en espacios colectivos. El intuito es contribuir para la formación continuada de maestros en el sentido de destacar la actualidad de la propuesta montessoriana en el contexto escolar.

Palabras clave: Educación. Montessori. Niños.

- Recebido em 23 janeiro de $2017 \bullet$ Aprovado em 31 de agosto $2018 \bullet$ e-ISSN: 2177-5796

DOI: http://dx.doi.org/10.22483/2177-5796.2019v21n1p203-220

Copyright @ 2019. Conteúdo de acesso aberto, distribuído sob os termos da Licença Internaonal da CreativeCommons - CC BY-NC-SA Atribuição Não Comercial (https://br.creativecommons.org/licencas/) - Permite distribuição e reprodução, desde que atribuam os devido créditos à publicação, ao autor(es) e que licenciem as novas criações sob termos idênticos. 


\section{Introdução}

Para Montessori (1966) é identificando as necessidades e as especificidades da criança na primeira infância que se conhece o homem na sociedade. Por considerar esse período relevante, devido às inúmeras possibilidades de aprendizagem, teceu duras críticas à forma como a sociedade tratava os infantes, sobretudo por não reconhecer suas particularidades.

Essa autora enfatizou que a sociedade não se preocupou, por muitos séculos, com a criança, já que a ignorava e a deixava, exclusivamente, sob a responsabilidade da família. Esta, por sua vez, oferecia-lhe somente os meios materiais e, muitas vezes, nem isso, exilando-a no mundo do esquecimento. Como consequência dessa indiferença, muitas crianças nasciam e morriam facilmente, sendo este considerado um fenômeno natural pela sociedade. Conforme Montessori (1966, p. 8) "a morte daqueles pequeninos parecia tão natural que as famílias já tinham habituado, segundo a ideia bastante espalhada de que aqueles meninos não morriam realmente, mas, subiam ao céu". Tal fenômeno, segundo a autora, ficou conhecido como matança normal dos inocentes devido ao número elevado de mortalidade infantil.

As crianças eram esquecidas em relação aos seus direitos e tidas como um incômodo para os adultos, além de não serem ouvidas por eles. Isso porque, os adultos não têm tempo de se ocupar delas, "pois vivem absorvidos pelas tarefas urgentes; pai e mãe são ambos forçados a trabalhar e, se o trabalho falta, a miséria oprime e amarfanha tanto as crianças como os adultos" (MONTESSORI, 1966, p. 13).

Na realidade, não existia um lugar apropriado para que a criança se sentisse valorizada e compreendida na sociedade, já que ela era privada do convívio com os pais e demais adultos e deveria ter um comportamento adequado aos olhos dos mais velhos, devendo "permanecer tranquila, em silêncio, sem tocar em coisa alguma, porque nada lhe pertence" (MONTESSORI, 1966, p. 14). A impressionante cegueira do adulto, demonstra a sua insensibilidade em relação aos cuidados com os filhos, resultado da sua própria educação, "já que ama as crianças, mas, inconscientemente, as despreza, provocando nelas um secreto sofrimento, espelho dos nossos erros e advertência para a nossa conduta" (MONTESSORI, 1966, p. 14).

Por outro lado, Montessori (1966) esclarece que a indiferença não acontecia somente no âmbito familiar, mas também em outras instâncias sociais, pois nas escolas por exemplo, as 
crianças estavam sujeitas a diferentes doenças causadas não só pela falta de higiene, mas também pelo trabalho ali desenvolvido. Doenças físicas, como problemas na coluna vertebral, devido à posição forçada da criança, que permanecia curvada por muito tempo, e a miopia, causada pelo esforço da visão num ambiente sem muita luz; além do esforço mental, oriundo dos estudos pesados, que oprimiam a criança pelo tédio e pelo cansaço nervoso, eram comuns (MONTESSORI, 1966).

A educação sempre foi sinônimo de castigo, já que há um moderno requinte de "crueldade no princípio ideal de reunir a família e a escola no mesmo simulacro de educação, princípio que se concretizou na organização da escola e da família para o castigo e tormento da criança" (MONTESSORI, 1966, p. 12). As punições que envolviam violências físicas e ofensas, assim como, privações de passatempos e prazeres como o brincar, fizeram, por muito tempo, parte da rotina tanto da família como da escola. Por isso, Montessori por meio de seus estudos, procurou romper com a concepção de criança como um adulto em miniatura e como um ser incompleto e atribuiu a ela uma natureza própria, pela qual é considerado como o embrião do adulto.

Desta maneira, esse estudo de caráter bibliográfico tem por finalidade apresentar o pensamento de Maria Montessori no que diz respeito ao período da infância e sua proposta de trabalho envolvendo a organização de um ambiente adequado para o aprendizado da criança em espaços coletivos.

Para uma melhor organização da exposição, o texto divide-se em duas seções, sendo que, na primeira, é realizada uma explanação geral sobre a concepção de Maria Montessori sobre infância e desenvolvimento infantil e, na segunda, são apresentados os princípios pedagógicos e a educação dos sentidos propostos pela autora. É importante ressaltar que a atualidade do pensamento de Montessori contribui para a superação de práticas que desconsideram a infância como um período de profundas transformações na vida das crianças. Além disso, considera-se neste trabalho, que as escolas infantis se constituem espaços fundamentais e necessários no processo de humanização das crianças e no desenvolvimento de suas diferentes linguagens. Para tanto, a formação inicial e continuada é necessária como um direito e um dever dos professores que atuam nessa etapa da educação básica.

\section{A concepção de infância e de desenvolvimento humano em Montessori}

Do ponto de vista histórico a indiferença natural provinda da família e da sociedade em 
relação às crianças datam séculos, visto que as relações entre essas e os adultos eram meramente formais. Na realidade, as especificidades da criança, suas particularidades e toda a sua originalidade na forma de conceber o mundo não eram sequer pensadas e reconhecidas pela figura do adulto.

O conflito entre essas duas gerações se tornou tão comum, que foi preciso uma intervenção científica para explicar como esse fenômeno se cristalizou nas relações entre um e outro. A ciência, portanto, foi a pioneira nesse processo, uma vez que denunciou, por meio de investigações, as relações estabelecidas entre as crianças e os adultos e como esses últimos tratavam os pequenos no seio familiar e na escola (MONTESSORI, 1966).

Desta maneira, um movimento social a favor da infância surgiu e se propagou no sentido de combater as inúmeras agressões cometidas contra as crianças ao longo dos séculos. Somente depois de se conscientizar sobre o número de óbitos entre as crianças, a sociedade passou a se organizar no sentido de cobrar da família e da escola os meios indicados pela ciência em relação aos cuidados com os pequenos.

A medicina contribuiu para isso quando apontou a higiene escolar como um fator importante para a promoção da saúde infantil. Montessori (1966) esclarece que a ciência contribuiu para o início de um movimento social em favor da infância e que os conceitos de higiene tiveram um papel importante no combate à mortalidade infantil. Isso porque, além de combater a mortalidade infantil, "demonstrou que as crianças eram vítimas de fadiga escolar; a higiene escolar descreve crianças desventuradas de espírito oprimido e inteligência fatigada, costas curvadas a peito estreito, crianças predispostas à tuberculose” (p. 9).

Somente no século XIX, quando os hábitos de higiene começam a se difundir entre as classes mais populares, que a vida das crianças toma nova feição, sobretudo quando os reformadores começam a considerá-las nos planos de urbanização, pois, "reservam-lhes jardins e terrenos para jogos na construção de praças e parques; pensa-se nas crianças quando se edificam teatros e publicam livros e jornais" (MONTESSORI, 1966, p. 12).

Montessori (1966) explica que foi muito rápido o progresso em relação aos cuidados e à educação das crianças e considera a Psicanálise como um campo de investigação importante e pioneira nas pesquisas sobre o subconsciente humano. Para a autora, "foi um estudo das reações psíquicas com origem para lá do que é consciente e que com a sua resposta trazem a superfície 
fatos secretos e realidades impensadas que revolucionam os velhos conceitos" (MONTESSORI, 1966, p. 21).

Apesar da importante contribuição de diferentes campos científicos no que diz respeito ao estudo do homem em sua evolução histórica, foi a Psicanálise que abordou, primeiramente, as origens das psicoses, numa fase precoce da infância, já que as recordações vindas do inconsciente demonstraram um sofrimento infantil diferente do normalmente conhecido. Na prática, a repressão exercida pelo adulto sobre a atividade espontânea da criança é a causa desse sofrimento, pois "a criança não pode expandir-se como conviria a um ser em formação, isto porque o adulto a reprime. A criança é um ser isolado na sociedade” (MONTESSORI, 1966, p. 27).

É importante ressaltar que o adulto percebe e analisa a vida psíquica da criança sempre tomando como base a própria vida psíquica, ou seja, o seu parâmetro é o padrão do adulto. Nesse sentido, a incompreensão se torna tão aparente que o mesmo passa a considerar a criança como um ser vazio, "[...] um ser inerte e incapaz, pelo qual tudo deve realizar; um ser sem guia interior, razão por que tem que guiá-la do exterior, passo a passo" (MONTESSORI, 1966, p. 31).

Por acreditar na capacidade de autoconstrução da criança, Montessori (1966) atribuiu ao adulto a responsabilidade de organizar o ambiente e criar as condições necessárias para que esse processo seja efetivado, isto é, para que as potencialidades sejam desenvolvidas. A criança, ao nascer, traz potencialidades construtivas que devem desenvolver-se por meio desse ambiente. Quando nasce, ela não vem desprovida no sentido de não ter qualidades psíquicas ou aptidões motoras prestáveis, mas tem, em si, potencialidades que determinam o seu desenvolvimento, a partir das condições e oportunidades oferecidas pelo mundo à sua volta (MONTESSORI, 1965). Por isso, ressalta que a criança, no início da vida, é considerada um embrião espiritual, ou seja, é dotada de uma dupla vida embrionária: uma que é chamada de pré-natal, semelhante à de outros animais, e outra chamada de pós-natal, exclusiva do ser humano.

Segundo a autora, a criança é o embrião do espírito, pois, no início, a vida psíquica é pequena, mas, gradualmente, em função das adaptações e flexibilizações que vão sendo vivenciadas, ela vai desenvolvendo funções psíquicas superiores. O processo de lentidão no desenvolvimento inicial da criança ocorre pela necessidade de elaboração especial das estruturas somáticas e psíquicas, as quais, por sua complexidade, exigem um tempo maior de processamento, sendo este essencial para o seu desenvolvimento individual. 
É importante ressaltar que a sua formação em medicina contribuiu para que defendesse uma educação voltada para o desenvolvimento humano com ênfase nos aspectos biológicos, por meio do tripé atividade-individualidade-liberdade que formava a base de seu trabalho. Para tanto, Montessori estabeleceu três períodos para o desenvolvimento humano, no qual o primeiro vai de zero a seis anos e se caracteriza pelo que nominou de "mente absorvente". Esse período se subdivide em dois momentos, sendo: "mente absorvente inconsciente", que vai de zero a três anos de idade, e "mente absorvente consciente", que vai de três a seis anos.

No período da "mente absorvente inconsciente", a absorção do ambiente pela criança acontece de maneira inconsciente, já que, ao nascer, ela não traz nenhuma capacidade pronta, mas potencialidades para serem desenvolvidas. A fase que vai dos três aos seis anos caracterizase pela absorção consciente da criança junto ao ambiente. Nesse momento, a linguagem e o movimento são relevantes, pois são os meios para o desenvolvimento psíquico. Esse período de construção dá continuidade ao anterior, já que a criança se utiliza das faculdades anteriores, como a memória, por exemplo, para interagir em seu meio.

Já a "mente absorvente consciente" é um tempo de grandes transformações, pois torna a criança habilitada para várias funções físicas e psíquicas que lhe permitirão o domínio do meio e de si mesma. É nesse período que Montessori (1965) ressalta a importância da aprendizagem das habilidades, pois chama a atenção para a qualidade do trabalho que deve ser desenvolvido nas escolas infantis. O segundo período, que chamou de "intermediário", corresponde à fase dos seis aos doze anos, e o terceiro período se subdivide em puberdade, que vai dos doze aos quinze anos, e adolescência, que compreende dos quinze aos dezoito anos.

A passagem da "mente absorvente" para o "período intermediário" é notável, já que a criança torna-se mais calma e vigorosa, tanto física como mentalmente, é o momento propício para a aquisição de informações culturais e científicas. É, também, um momento para a formação da consciência moral, uma vez que a criança já percebe a diferença entre o bem e o mal. O desenvolvimento da sociabilidade se dá, exatamente, nesse momento, pois a criança amplia seu círculo de amizades e participa de atividades coletivas.

No terceiro e último período do desenvolvimento humano, que se caracteriza pela puberdade e pela adolescência, o jovem passa por mudanças significativas no plano físico e mental. Dessa forma, ao atingir, já no final dessa fase, a maturidade, o mesmo chega à plenitude de seu desenvolvimento e adquire a consciência social. 
Em relação ao primeiro período do desenvolvimento humano, proposto por Montessori (1965), o conceito de "mente absorvente" ou "mneme" é utilizado por ela para explicar o desenvolvimento infantil e se refere à força mnêmica inconsciente da criança, responsável pela retenção das impressões absorvidas desde o período inicial da infância. Na realidade, o período da "mente absorvente" caracteriza-se pela absorção do ambiente pela criança, que acontece por meio de sua vida sensorial, motora, afetiva e cognitiva.

Nesse período, formam-se a inteligência e as demais faculdades psíquicas, inclusive a personalidade da criança. A “mneme" é diferente da memória usual por ser inconsciente, já que seus conteúdos são absorvidos na relação com o mundo externo e permanecem no sujeito, fazendo parte de sua personalidade. A língua materna, os hábitos e costumes, por exemplo, são adquiridos por meio desse processo.

Montessori (1966) enfatiza que, na infância, a criança passa por períodos chamados "sensíveis", durante o processo do seu desenvolvimento psíquico, e faz, nesse decurso, descobertas significativas ao se relacionar com o mundo exterior. Cada esforço representa um acréscimo de poder e, somente quando se completa essa aquisição, é que aparecem, no "período sensível", o auge da indiferença e a fadiga, como assinala a autora:

\footnotetext{
Mas quando se extingue uma dessas paixões psíquicas acendem-se outras chamas, decorrendo assim a infância, de conquista em conquista, em contínua vibração vital que todos reconhecemos, chamando-lhe alegria e felicidade natural infantil; [...] mas, terminando o período sensível, as conquistas intelectuais passam a depender de uma atividade reflexiva, do esforço da vontade e trabalho de pesquisa, e no topor da indiferença nasce a fadiga do trabalho (MONTESSORI, 1966, p. 68).
}

Se durante esse período algum obstáculo se opõe à sua atividade vital, dá-se uma perturbação de comportamento, daí surge o embate com o adulto, que, por não entender essa fase, considera como um capricho infantil algumas atitudes da criança. Os caprichos são, na realidade, expressões de uma perturbação interna, de um desejo insatisfeito que promove um estado de tensão na criança. Esses caprichos do "período sensível” são expressões de necessidades insatisfeitas, que sinalizam para uma situação adversa e que desapareceriam se houvesse possibilidade de compreensão e satisfação. São esses momentos que é possível se desvendar os mistérios da alma infantil e compreender o seu comportamento (MONTESSORI, 1966).

No "período sensível”, o desenvolvimento não acontece por acaso, pois é guiado por sentidos transitórios correspondentes a instintos temporários, aos quais está ligada a aquisição de 
PASCHOAL, Jaqueline Delgado; MACHADO, Maria Cristina Gomes. A pedagogia de Maria Montessori para a educação na infância.

várias características. Considerando-se que esses eventos são possibilitados graças à intervenção do ambiente externo, o qual, embora ofereça as condições necessárias para a vida, como a nutrição e o oxigênio para a respiração, não tem valor construtivo, pois são os sentidos interiores que orientam as escolhas das crianças, fazendo com que as mesmas sejam sensíveis a algumas situações e indiferentes a outras, segundo explicação de Montessori (1966).

A linguagem é considerada pela autora como um instrumento fundamental de interação adulto e criança. Nesse período que corresponde à sua fase de maior sensibilidade, entretanto, a criança ainda não consegue externalizar verbalmente seus sentimentos, que permanecem secretos, a não ser por meio de manifestações expressivas ou gestuais. Neste sentido, Montessori (1966), afirma que "a única coisa que pode fazer-nos avaliar, do exterior, o estado sensitivo da criança é o sorriso e, manifesta alegria quando lhe são dirigidas breves palavras" (p. 73).

Um outro elemento importante, no "período sensível" da criança, diz respeito à ordem externa, não a que se relaciona com as questões de regras, mas a que se refere à organização do ambiente. No cotidiano, a desordem do espaço físico pode acarretar, na criança, sofrimento e agitação, fazendo com que ela apresente um comportamento de choro e descontentamento frente aos adultos. O exemplo a seguir demonstra como acontecem esses eventos, na relação entre a criança e o ambiente em que vive:

A principal personagem é uma menina de cerca de seis meses de idade. À nursery, isto é, ao quarto onde habitualmente a criança permanece, chega um dia em visita uma senhora que põe o chapeuzinho de sol sobre a mesa. A menina parece agitar-se; claro que não o faz pela senhora, mas por causa do chapéu, porque depois de longamente o ter olhado começa a chorar. A senhora, interpretando como desejo da criança ter o chapéu, apressase a levar-lhe, acompanhando o ato com os sorrisos e carinhos que é costume proporcionar às crianças. Mas a pequenina empurra o objeto e continua a gritar. Seguemse outras tentativas análogas, mas a menina agita-se cada vez mais. Que fazer? Eis que se esboça um daqueles caprichos precoces que se apresentam quase desde nascença. Subitamente a mãe da criança, que tinha alguns conhecimentos das manifestações psíquicas de que falávamos, tira o chapéu da mesa e leva-o para o compartimento vizinho. A criança acalma-se imediatamente (MONTESSORI, 1966, p. 84).

Na realidade, o sofrimento da criança era o chapéu sobre a mesa, ou seja, o objeto fora do lugar de costume que perturbava. É importante mencionar que essa sensibilidade relacionada ao ambiente externo vai desaparecendo com o avanço da idade.

Um outro exemplo, que ilustra essa fase sensível na vida da criança, deixa claro que a desorganização do ambiente externo pode ser um fator de descontentamento por parte de algumas 
PASCHOAL, Jaqueline Delgado; MACHADO, Maria Cristina Gomes. A pedagogia de Maria Montessori para a educação na infância.

crianças e de indiferença para outras, dependendo da situação. Trata-se de um menino mais velho, com um ano e meio de idade que passeava com a mãe, junto a um pequeno grupo de visitantes, na passagem para a gruta de Nero, em Nápoles, assim narrados:

Conosco estava uma jovem senhora que trazia uma criança na realidade demasiado pequena para poder percorrer a pé aquele caminho subterrâneo que atravessa toda uma colina. Daí a algum tempo a criança parou e a senhora pegou-lhe no colo. Mas não tinha calculado as próprias forças. Como sentisse calor, deteve-se para tirar o casaco e pô-lo no braço; e, com esse estorvo, pegou também o menino. Este desatou a chorar cada vez com mais intensidade e desespero. Em vão a mãe procurava acalmá-lo; via-se que estava exausta e começava a enervar-se. à sua volta ficaram todos perturbados e naturalmente ofereceram ajuda. A criança passava de colo para colo, cada vez mais agitada e à força de exortações e de gritos a situação piorou. Era evidente a necessidade de a mãe tornar a pegar nela. Mas o garoto chegara ao auge do que se chama capricho, e o caso parecia desesperado. Nesse momento interveio o guia com sua energia de homem decidido e agarrou a criança nos braços robustos. Houve então uma reação violenta da criança. Eu pensava que estas reações têm sempre uma causa psíquica correspondente a uma sensibilidade interna e fiz uma tentativa. Aproximei-me da mãe da criança e pedi-lhe: "minha senhora, permite-me que a ajude a vestir o casaco?". Ela olhou-me espantada porque ainda tinha calor, mas, confusa, correspondeu ao pedido e deixou-se vestir. A criança acalmou logo. Cessaram as lágrimas e a agitação (MONTESSORI, 1966, p. 85).

Esses exemplos indicam a intensidade dos comportamentos apresentados pelas crianças, os quais, normalmente, acontecem muito precocemente nos primeiros anos de vida. Na realidade, a ordem das coisas e a manutenção dos objetos sempre no mesmo lugar facilitam a orientação e o domínio da criança em relação ao ambiente, e "[...] tal formação construtiva não se efetua segundo uma fórmula vaga, porque exige uma orientação precisa e determinada" (MONTESSORI, 1966, p. 87).

No que diz respeito ao desenvolvimento, a natureza confere à criança a sensibilidade à ordem. Essa construção se dá internamente e não se reduz à distinção entre os objetos, abrange as relações entre eles. Nesse sentido, a inteligência da criança não se estrutura a partir do exterior, mas se inicia quando, internamente, a mesma se apropria de imagens do ambiente, captando-as por meio dos sentidos, o que é muito diferente da pura capacidade de receber essas imagens como um espelho do ambiente externo.

Esse desenvolvimento, segundo a autora, se dá, justamente, pela sucessão dos "períodos sensíveis" que ocorrem na relação da criança com o meio. Na transição entre um período e outro, concorrem as chamadas "fases nebulosas", que seriam as energias criativas que orientam a criança na absorção do ambiente, dando-lhe o substrato necessário para o desenvolvimento, ou seja, para que as potencialidades possam ser materializadas como uma evolução efetiva. Um 
exemplo seriam as energias nebulosas da linguagem infantil, que tornam a criança capaz de absorver os sons da língua falada e outras propriedades que lhe permitem internalizar a língua materna.

Para a conclusão dessas premissas, os estudos de Montessori (1966) inspiraram-se nos fundamentos científicos dos médicos Jean-Marie Gaspard Ytard, otólogo francês, e Édouard Séguin, os quais possibilitam a estruturação do seu trabalho na clínica psiquiátrica, junto às crianças deficientes mentais, e a elaboração de uma proposta pedagógica que priorizasse o desenvolvimento infantil dessas crianças e, posteriormente, das crianças normais. Sua proposta pedagógica teve forte influência desses estudos, uma vez que o pano de fundo de toda a sua obra foi a de busca pelo estabelecimento de uma relação entre a sensação, o intelecto e a vontade da criança, desde que essa educação acontecesse num ambiente de liberdade e estímulo.

\section{Princípios pedagógicos e a educação dos sentidos propostos por Montessori}

Apesar de trabalho de Montessori (1966) ter se iniciado com crianças deficientes, defendia, em sua pedagogia, que entre essas crianças e as normais existiria uma diferenciação de comportamentos e aprendizagens somente no que diz respeito ao ritmo e ao tempo. Entre as deficientes, esses eventos aconteceriam de maneira mais lenta, enquanto que, entre as normais, esses eventos aconteceriam normalmente; tendo as duas a possibilidade de desenvolvimento e aprendizagem.

Isso posto, deixa claro que, no início de sua carreira, ao trabalhar com as crianças, teve "logo a intuição de que esses métodos de ensino não tinham nada de específico para a instrução de crianças excepcionais, mas continha princípios de uma educação mais racional do que aquelas que até então vinham sendo usados” (MONTESSORI, 1965, p. 28). Assim, ela elaborou uma "Pedagogia Científica" a partir de sua experiência com crianças pobres, a qual foi desenvolvida no bairro de San Lorenzo, em Roma, e retratada em sua obra "A Criança", a origem do seu método. Conforme relata:

Foi em seis de janeiro de 1906, quando inaugurou a primeira escola para crianças pequenas normais de três a seis anos, não posso dizer com meu método, porque ele ainda não existia, mas, estava prestes a nascer. Nesse dia estavam ali apenas 50 criancinhas muito pobres de aspecto tosco, tímidas, choronas, quase todas filhas de analfabetos, que tinham sido entregues aos meus cuidados (MONTESSORI, 1966, p. 165). 
Seu projeto inicial tinha como objetivo juntar os filhos pequenos dos operários que habitavam um prédio popular, para que não ficassem ociosos durante o dia. Para isso foi fornecida uma sala do próprio prédio, e que serviria de espaço para a organização de diferentes atividades junto às crianças, "solicitaram-me que me encarregasse dessa instituição que poderia ter um belo futuro; tive a indefinível impressão de que iria nascer uma obra grandiosa" (MONTESSORI, 1966, p. 165). A proposta da Pedagogia Científica baseava-se na necessidade de se ir além do diagnóstico dos problemas educacionais, no qual a ideia era propor uma aprendizagem por meio dos sentidos, respeitando-se, sempre, a individualidade de cada criança e o ritmo do seu desenvolvimento.

Segundo Angotti (2007, p. 105) "o ideal de escola nessa pedagogia reside em propiciar e garantir as manifestações espontâneas e da personalidade da criança, de permitir e aflorar do livre desenvolvimento da atividade no ser humano em sua infância”. Para essa autora as pesquisas de Montessori foram importantes para sua época, e ao mesmo tempo se mantém inovadora ainda hoje, sobretudo em relação ao método ativo para a preparação racional dos indivíduos à sensações e percepções. É a educação baseada no desenvolvimento dos sentidos, que guarda importante valor pedagógico e científico, já que o desenvolvimento dos sentidos precede o das atividades superiores intelectuais (ANGOTTI, 2007).

Por meio da observação, Montessori (1966) conseguiu compreender as manifestações das crianças no aspecto relacionado à concentração, quando essas interagiam com os exercícios propostos. Com base em diferentes experiências vivenciadas com crianças pobres, no ano de 1907, inaugurou-se a primeira "Casa dei Bambini”. Montessori (1966) enfatizou que o primeiro fenômeno que chamou sua atenção foi o de uma menina de cerca de três anos que fazia o exercício de encaixar e destacar os pequenos cilindros dos encaixes sólidos; “[...] fiquei surpreendida de ver uma menina tão pequena repetir interminavelmente, e, com profundo interesse, um exercício. Não se notava qualquer progresso na rapidez e destreza da execução, era uma espécie de moto-contínuo" (p. 166).

Por meio da observação a autora contava os exercícios no sentido de verificar até onde podia resistir à concentração da criança, “com rápido movimento a menina tinha pegado nos seus objetos e, pondo-os em cima dos joelhos, continuou no mesmo trabalho; parece nem se quer, ter dado conta de todas as manobras que não tinham conseguido perturbá-la” (MONTESSORI, 1966, 
p. 172). Essa concentração da criança era acompanhada por um movimento rítmico da mão em volta de um objeto preciso, que chamou de repetição do exercício.

Desta maneira, afirmava que, independentemente da opção metodológica do professor, a ação educativa deve propiciar as "condições do ambiente que favoreçam a aparição dos caracteres normais que estejam ocultos na criança; para tal fim, basta apenas, afastar os obstáculos" (MONTESSORI, 1966, p. 201). Um ambiente adequado, um bom professor e material científico são os três pontos que podem auxiliar a criança nos momentos de aprendizagem. Para tanto, o ponto de partida para a promoção do desenvolvimento das manifestações espontâneas e da personalidade da criança deveria ser a observação e o estudo da mesma, em sua livre ação. Isso porque o método de observação "há de fundamentar-se sobre uma só base: a liberdade de expressão que permite às crianças revelar-nos suas qualidades e necessidades, que permaneceriam ocultas ou recalcadas num ambiente infenso à atividade espontânea" (MONTESSORI, 1965, p. 42).

$\mathrm{Na}$ sua perspectiva o espaço físico e o ambiente são elementos importantes, como o padrão de mobília escolar, por exemplo, que deveria corresponder à necessidade da criança de agir de maneira inteligente no espaço, como pode ser observado na figura 1, que mostra uma sala montessoriana em Amsterdã, na década de 1930.

Figura 1 - Sala organizada com base na orientação espacial de Montessori

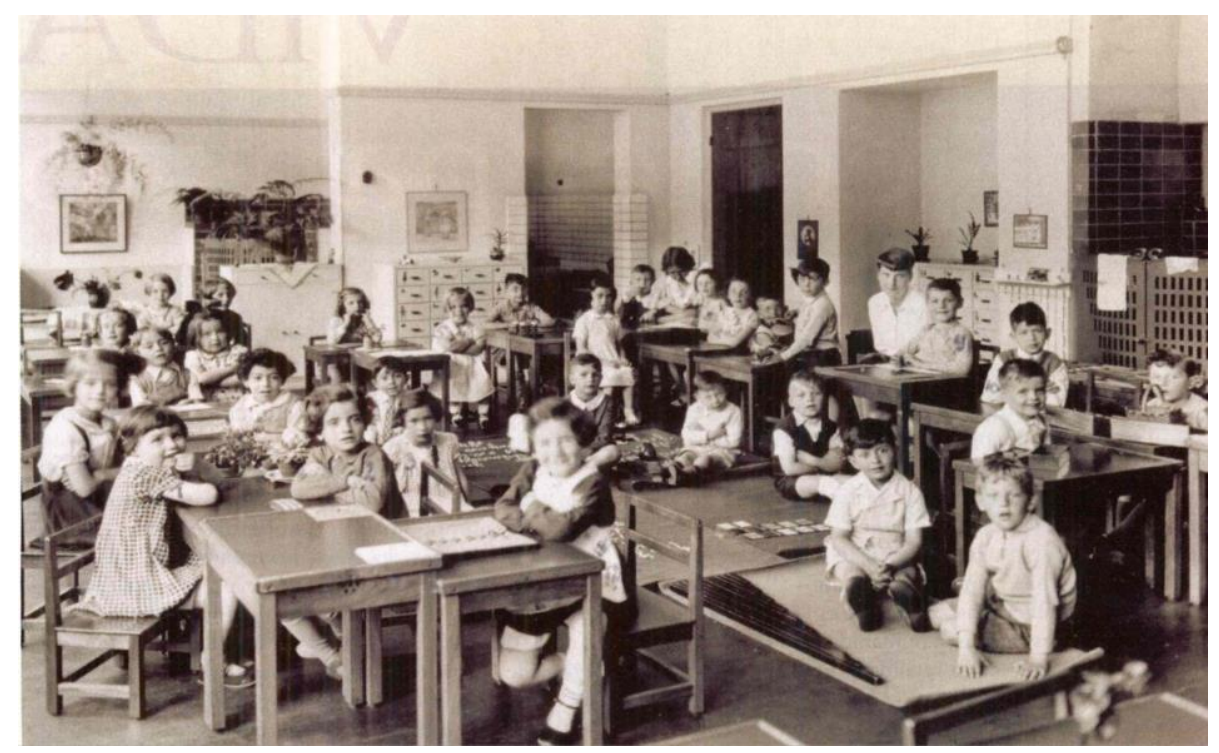

Fonte: HILSDORF, M. L. S. Vida em expansão. Viver Mente e Cérebro, São Paulo, n. 3, p. 17-27, 2005. Suplemento especial: Maria Montessori. (Coleção Memória da Pedagogia). p.18. 
A mobília deve ser adequada à idade e ao tamanho da criança, como, por exemplo: mesas leves; cadeirinhas de madeira que podem ser carregadas de um lado para o outro; pias baixas, acessíveis às crianças; estantes baixas com materiais de desenvolvimento para trabalhar com a educação dos sentidos; lousas e pequenos quadros sobre a vida em família, entre outros materiais que devem fazer parte da organização do espaço na sala de aula.

As mesas, as cadeiras, as pequenas poltronas, leves e transportáveis, permitirão à criança, escolher a posição que lhe agrada; ela poderá, por conseguinte, instalar-se comodamente, sentar-se em seu lugar: isto lhe constituirá, simultaneamente, um sinal de liberdade e um meio de educação (MONTESSORI, 1965, p. 44).

Essa liberdade de movimento exige outro olhar do professor em relação à disciplina em sala de aula, pois, num ambiente onde a criança almeja transitar livremente com os materiais que lhe são oferecidos, não se pode coibi-la da livre movimentação, uma vez que "o indivíduo é senhor de si mesmo, e, em decorrência, pode dispor de si ou seguir uma regra de vida" (MONTESSORI, 1965, p. 45). A disciplina não é fácil de ser praticada no cotidiano de uma sala de aula, já que demanda uma postura diferenciada do professor, com base em uma concepção mais inovadora de educação, pois "requer-se da mestra uma técnica especial para introduzir a criança nesta via de disciplina em que ela deverá depois, caminhar a vida toda, em marcha incessante para a perfeição" (MONTESSORI, 1965, p. 45).

A liberdade deve ter como limite, no entanto, o interesse coletivo. Isso quer dizer que cabe ao professor interferir quando a criança apresentar um comportamento que prejudica o outro. O objetivo, nesse contexto, é disciplinar o comportamento e não imobilizar a criança ou torná-la passiva. O movimento da criança disciplinada torna-se, com o tempo, mais coordenado e perfeito, pois esta aprende a controlar os seus próprios gestos e, por sua vez, “a mestra tirará suas conclusões observando como as crianças substituem seus primeiros movimentos desordenados por movimentos espontâneos disciplinados" (MONTESSORI, 1965, p. 50).

Para Araújo e Araújo (2007), a liberdade dos alunos deve ser o pivô fundamental da pedagogia científica, pois permite o desenvolvimento das manifestações espontâneas individuais da criança.

O seu labor é feito de atividade, ela cresce com exercício e movimento: a criança exercita-se e move-se fazendo experiências e, assim como coordena os seus movimentos e vai registrando, vindas do mundo exterior, as emoções que plasmam sua inteligência, vai conquistando a linguagem com fadiga, com milagres de atenção e esforços iniciais, que só lhe são possíveis a ela (ARAÚJO; ARAÚJO, 2007, p. 127). 
$\mathrm{Na}$ realidade, a finalidade de se possibilitar a livre movimentação, em sala de aula, é conduzir a criança, paulatinamente, rumo à independência necessária em um indivíduo adulto, ou seja, rumo à autonomia. Um dos pilares da proposta montessoriana é o exercício da escolha, ou seja, o desenvolvimento dessa habilidade permite as crianças o desejo de se tornarem independentes. É importante ressaltar que neste processo elas vão construindo sua identidade individual. Por isso a importância de um ambiente bem organizado, que ofereça múltiplas oportunidades para que possam optar por uma ou outra atividade.

Assim, para ser produtiva, qualquer atividade pedagógica deve proporcionar um avanço no caminho da independência, ou seja, atividades simples como andar, correr, subir e descer escadas, pegar objetos no chão, vestir-se, pentear-se, alimentar-se e lavar-se devem ser priorizadas no cotidiano escolar para que as crianças se tornem mais independentes. A figura 2 apresenta uma escola montessoriana em Berlim, na década de 1928, no momento do lanche que é servido por elas mesmas, expressando o sentido da atividade em grupo.

Figura 2 - Hora do lanche

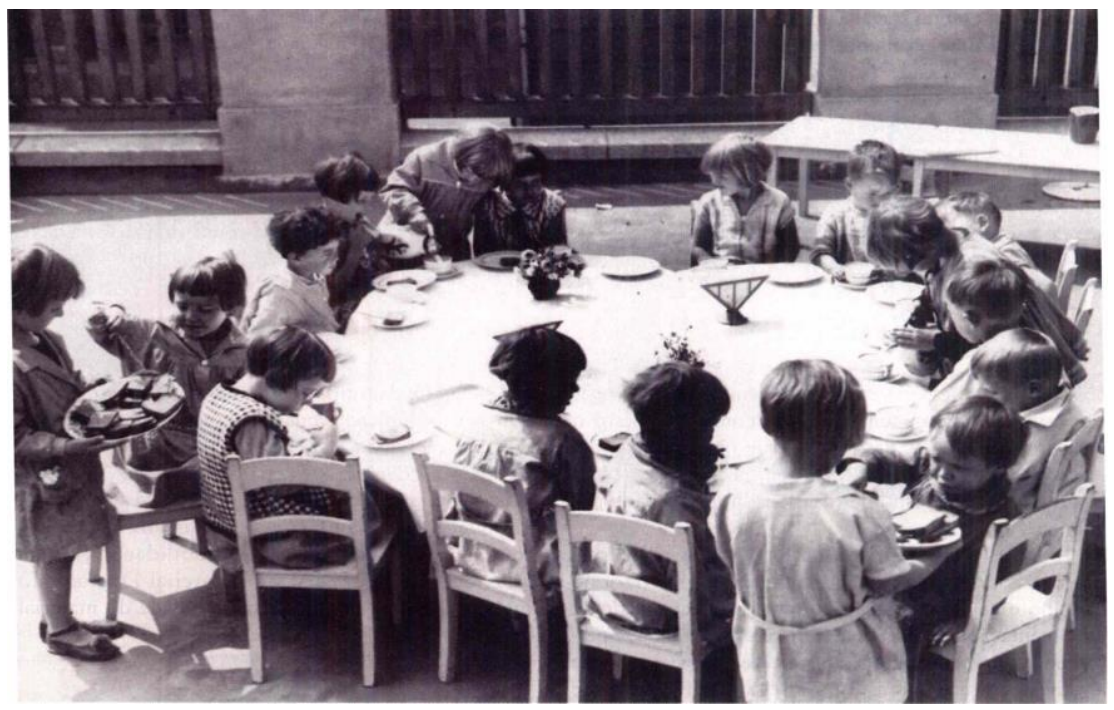

Fonte: LIMA, Edmara de. O exercício da autonomia. Viver Mente e Cérebro, São Paulo, n. 3, p. 67-75, 2005. Suplemento especial: Maria Montessori. (Coleção Memória da Pedagogia). p. 69.

O ritmo de cada criança deve ser respeitado, no momento desses eventos, uma vez que os prêmios e os castigos devem ser abolidos da sala de aula (MONTESSORI, 1965). Premiar os melhores e punir aqueles que apresentam um comportamento inadequado não ajuda a criança a crescer, pois instiga nela a rebeldia. 
A classe vem a ser um meio ambiente preparado no qual tem lugar o estudo positivo. As suas atividades devem levar sempre a realização do potencial da criança. Quando fracassamos em aprender, chega o castigo natural que Montessori define, como a perda da consciência do nosso próprio poder e grandeza que constitui a qualidade da humanidade (ARAÚJO; ARAÚJO, 2007, p. 122).

A tarefa do professor é a de estruturar a classe de forma a dar significado às experiências da criança, desse modo, o plano de estudo "deve ser desenvolvido por antecipação como uma série de tarefas evolutivas que capacitam a criança quanto antes para o crescimento necessário" (ARAÚJO; ARAÚJO, 2007, p. 123).

Quando Montessori (1965) defende a liberdade infantil, ela não está se referindo aos atos externos desordenados que as crianças realizam, mas à liberdade como um elemento fundamental para o desenvolvimento normal da criança. Neste sentido, orienta que "em primeiro lugar, pensese em criar um ambiente adequado, onde a criança possa agir tendo em vista uma série de interessantes objetivos, canalizando, assim, dentro da ordem, sua irreprimível atividade, para o aperfeiçoamento" (MONTESSORI, 1965, p. 58).

A criação de um ambiente adequado, no entanto, só pode contribuir para o desenvolvimento da criança, se, acima de tudo, for higiênico, já que a saúde influi sobre o coeficiente psíquico da mesma. Portanto, "urge construir um ambiente que comporte as melhores condições de higiene possíveis" (MONTESSORI, 1965, p. 62).

Sendo prioritária uma organização espacial que promova a livre movimentação da criança, a educação dos movimentos se faz necessária no contexto da escola, uma vez que contribui, de maneira eficaz, para o desenvolvimento dos músculos e da personalidade infantil. $\mathrm{Na}$ realidade, a criança pequena está em constante movimento, pois ela se mexe sem parar, arrasta-se pelo pavimento "corre e quer pegar em tudo; aos nove anos o garoto caminha e se agita sem sentir a necessidade de se arrastar pelo chão ou pegar tudo o que encontra" (MONTESSORI, 1965, p. 79). Assim:

Atravessam o período da vida em que é necessário tornar-se senhor dos próprios atos. Sem que lhe possamos perceber as íntimas razões fisiológicas, as forças musculares e nervosas estão agora naquela fase em que se processa a paulatina coordenação dos movimentos (MONTESSORI, 1965, p. 85).

Considerando-se a enorme mobilidade infantil, a educação dos sentidos, proposta por Montessori (1965), faz-se necessária no contexto da sala de aula, uma vez que, por meio dela, a criança se desenvolve não só cognitivamente, mas, sobretudo, fisicamente, e adquire novas 
aprendizagens. Dessa maneira, a educação sensorial precede as atividades intelectuais mais complexas, uma vez que, no período da infância, a inteligência está em plena formação.

O desenvolvimento dos sentidos poderá auxiliar a criança mediante "uma graduação e adaptação dos estímulos, assim, deve-se auxiliá-la na formação da linguagem, antes que esta esteja completamente desenvolvida" (MONTESSORI, 1965, p. 98).

No período que vai dos três aos seis anos de idade, a criança passa por um crescimento físico muito rápido, no qual as atividades psíquicas e sensoriais também se formam. A criança sente-se atraída pela observação do ambiente, devendo, o professor, incentivá-la em situações em que os sentidos são aflorados. Os sentidos nada mais são, segundo a autora, que órgãos de apreensão das imagens do mundo externo, assim como as mãos, por exemplo, que tocam e manuseiam objetos fazendo com que a criança reconheça suas diferentes funções na vida prática. Os materiais como quadros que ensinam a abotoar, dar laços, fazer nós; lavabos para as mãos; panos para limpar o chão; escovas para limpar sapatos, tapetes, vassouras e espanadores para tirar o pó deve estar disponível na sala de aula.

Assim, as tarefas domésticas devem, necessariamente, fazer parte do cotidiano das escolas infantis, já que são ocupações que possibilitam a ela, o desenvolvimento da inteligência e a aquisição da cultura.

Estender tapetes e enrolá-los, depois de usados; estender a toalha sobre a mesa à hora das refeições, dobrando-a depois e colocando-a em seu devido lugar; alimentar-se polidamente, retirar pratos e talheres, lavá-los e colocá-los no armário, são trabalhos cujas dificuldades são graduadas e que exigem um desenvolvimento gradual do caráter (MONTESSORI, 1965, p. 59).

$\mathrm{Na}$ realidade, essas atividades rotineiras são "sistemas combinados para educação dos sentidos e para o ensino do alfabeto, números, escrita e aritmética, na qual esse conjunto de objetos denomina-se, material de desenvolvimento" (MONTESSORI, 1965, p. 59).

A figura 3 ilustra uma atividade relacionada à vida prática denominada "quadros para abotoar", utilizados em gestos repetitivos, cuja função é desenvolver a habilidade de amarrar, dar laços, abrir e fechar diferentes tipos de fechos, botões presilhas e zíperes. 
Figura 3 - Quadro de abotoar

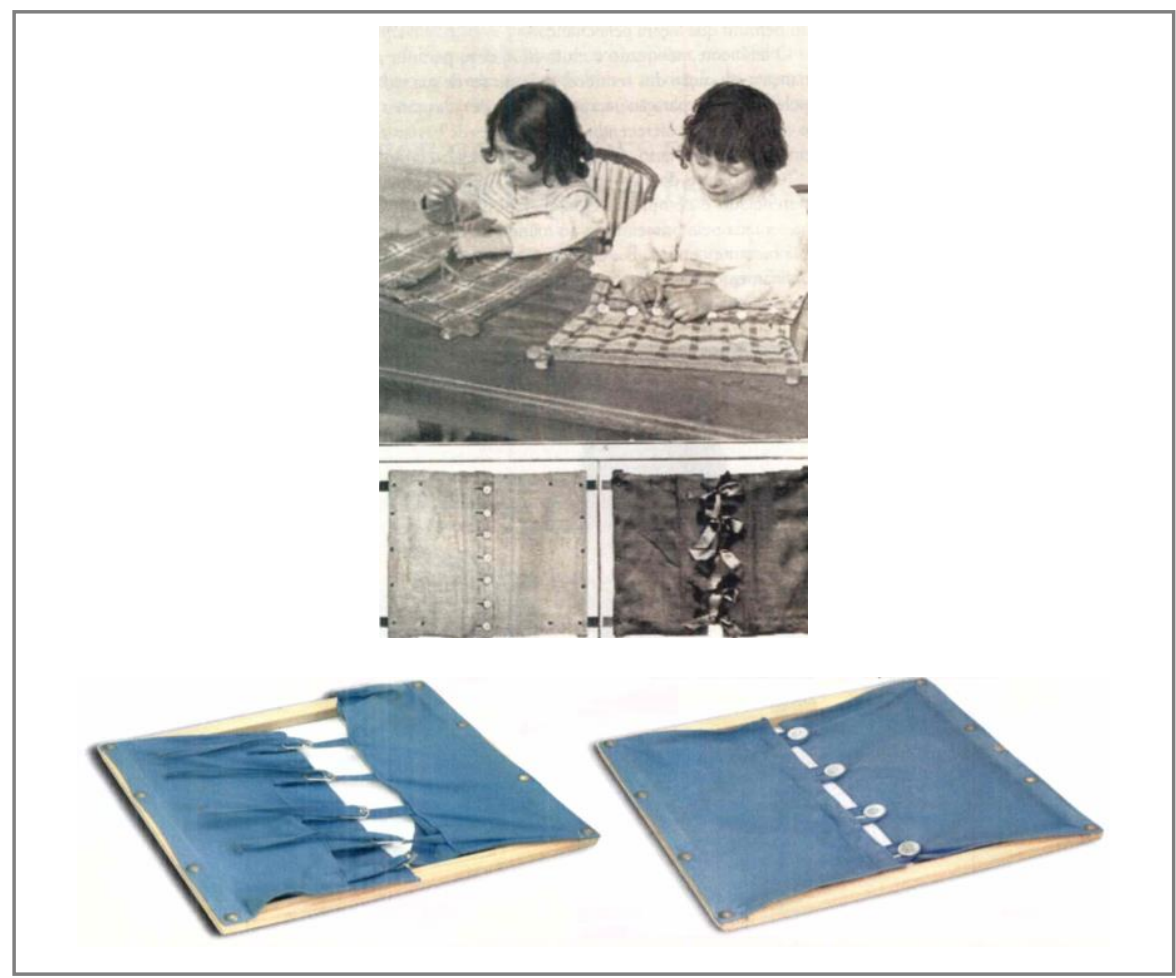

Fonte: ANGOTTI, Maristela. Espaços de liberdade. Viver Mente e Cérebro, São Paulo, n. 3, p. 54-65, 2005. Suplemento especial: Maria Montessori. (Coleção Memória da Pedagogia). p. 62.

É importante ressaltar que, a partir dessas orientações teórico-metodológicas, a autora desenvolveu novas técnicas para a educação sensorial com o objetivo de estimular o desenvolvimento intelectual de crianças, em suas diferentes faixas etárias.

\section{Considerações finais}

Montessori (1965) ressaltou a importância da formação do professor, para que este pudesse ter condições necessárias para conhecer cada criança e suas especificidades, uma vez que é ele quem possibilita à mesma a definição de seus próprios passos e de suas escolhas, de acordo com o seu interesse natural. Assim, cabia ao professor a preparação do ambiente e a apresentação dos materiais, de modo a permitir à criança a livre movimentação e a liberdade de escolha dentro de cada atividade proposta; daí a importância do seu conhecimento acerca da criança por meio da observação de seus interesses e necessidades.

Essa nova forma de conceber o desenvolvimento da criança e o modo como essa interage com o mundo que a cerca, possibilitou a Montessori (1965) a criação de diferentes materiais para 
PASCHOAL, Jaqueline Delgado; MACHADO, Maria Cristina Gomes. A pedagogia de Maria Montessori para a educação na infância.

subsidiarem o seu método. Seu trabalho ficou conhecido tanto na Itália como em outros países e chegou ao Brasil por volta de 1910, expandindo-se nas escolas brasileiras durante as primeiras décadas do século XX e XXI.

\section{Referências}

ANGOTTI, Maristela. Maria Montessori: uma mulher que ousou viver transgressões. In: OLIVEIRAFORMOSINHO, Júlia; KISHIMOTO, Tizuko Morchida; PINAZZA, Mônica Apezzato. (org.).

Pedagogias(s) da infância: dialogando com o passado: construindo o futuro. Porto Alegre: Artmed, 2007. p. 95-113.

ARAÚJO, Joaquim M. de; ARAÚJO; Albert F. Maria Montessori: infância, educação e paz. In: OLIVEIRA-FORMOSINHO, Júlia; KISHIMOTO, Tizuko Morchida; PINAZZA, Mônica Apezzato. (Org.). Pedagogias(s) da infância: dialogando com o passado: construindo o futuro. Porto Alegre: Artmed, 2007. p. 116-144.

MONTESSORI, Maria. A criança. 4. ed. Lisboa: Portugália, 1966.

MONTESSORI, Maria. Pedagogia cientifica: a descoberta da criança. São Paulo: Flamboyant, 1965. 